\title{
Measurement of the water vapour vertical profile and of the Earth's outgoing far infrared flux
}

\author{
L. Palchetti, G. Bianchini, B. Carli, U. Cortesi, and S. Del Bianco \\ Istituto di Fisica Applicata "Nello Carrara" - Consiglio Nazionale delle Ricerche IFAC-CNR, Sesto Fiorentino, Firenze, \\ 50019, Italy
}

Received: 18 October 2007 - Published in Atmos. Chem. Phys. Discuss.: 10 December 2007

Revised: 13 May 2008 - Accepted: 13 May 2008 - Published: 6 June 2008

\begin{abstract}
Our understanding of global warming depends on the accuracy with which the atmospheric components that modulate the Earth's radiation budget are known. Many uncertainties still exist as regards the radiative effect of water in the different spectral regions, among which is the far infrared, where very few observations have been made. An assessment is shown of the atmospheric outgoing flux obtained from a balloon-borne platform with wideband spectrallyresolved nadir measurements at the top of the atmosphere over the full spectral range, from 100 to $1400 \mathrm{~cm}^{-1}$, made by a Fourier transform spectrometer with uncooled detectors. From these measurements, we retrieved 15 pieces of information regarding water vapour and temperature profiles and surface temperature, with a major improvement in our knowledge of water vapour in the upper troposphere. The retrieved atmospheric state made it possible to calculate the emitted radiance also at frequencies and zenith angles that have not been observed and to determine the outgoing spectral radiation flux. This proves that spectrally resolved observations can be used to derive accurate information on the integrated flux. While the retrieved temperature was in agreement with ECMWF analysis, the retrieved water vapour profile differed significantly; depending on the time and the location, the derived flux in the far infrared $\left(20-600 \mathrm{~cm}^{-1}\right)$ differed by $2-3.5 \mathrm{~W} / \mathrm{m}^{2}$ from that calculated using ECMWF. The error with which the far infrared flux is determined by REFIR-PAD is about $0.4 \mathrm{~W} / \mathrm{m}^{2}$ and is caused mainly by calibration uncertainties, while detector noise has a negligible effect. This proves that uncooled detectors are adequate for top-of-the-atmosphere radiometry.
\end{abstract}

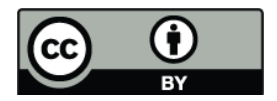

Correspondence to: L. Palchetti (1.palchetti@ifac.cnr.it)

\section{Introduction}

Water is the principal molecule that governs the climate on Earth. This is because, through the hydrological cycle, it is involved in all phenomena from energy transport to radiative effects governing the climate system (Pierrehumbert, 2002). Atmospheric water, in the form of both vapour and clouds, is the most important greenhouse component that traps the outgoing longwave radiation (OLR) (Harries, 1996). Its main contribution to climate changes is through feedback processes that occur as a consequence of a man-induced temperature variation driven by the increased $\mathrm{CO}_{2}$ concentration. Moreover, it has recently been found that long-term increases in stratospheric water vapour may also be considered to be in part a forcing term (Held and Soden, 2000). Changes in the distribution of water vapour and in the associated radiative forcing and feedback are well recognised as fundamental processes that are not known with sufficient accuracy in climate research and in numerical weather prediction (Lindzen, 1990; Chahine, 1992; Harries, 1997; Stuber et al., 2005). The 2007 IPCC (Intergovernmental Panel on Climate Change) report identifies the estimate of the strength of different feedbacks as a key uncertainty in global circulation model predictions (Randall et al., 2007).

Despite its prominent spectroscopic signatures in the infrared, the quantitative measurement of the water vapour volume mixing ratio (VMR) is complicated by its variability and its strong vertical (and, to a lesser extent, horizontal) concentration gradients. Furthermore, the spectroscopy of water vapour also poses some problems. The high concentration of this species in the lower troposphere makes relevant several spectroscopic processes (self and foreign broadening, pressure shift, and continuum absorption) (Tobin et al., 1999)

Published by Copernicus Publications on behalf of the European Geosciences Union. 
that are difficult to observe in laboratory conditions and thus require a field validation. Within this context, Sinha and Harries (1995) pointed out the lack of validation of far infrared (FIR) model line parameters of water vapour in atmospheric conditions, and stressed that FIR parameterisation in climate models should be validated by means of observational programmes.

The radiative balance of the troposphere is strongly influenced by radiative cooling due to water vapour emission in the FIR. The water vapour rotational band is extremely intense, especially at band centre around $200-300 \mathrm{~cm}^{-1}$, and so emits to space from the upper troposphere. Atmospheric flux calculations (Clough et al., 1992) have shown that perturbations to upper tropospheric water vapour (pressures of $<500 \mathrm{hPa}$ ) exert a peak response in the FIR, and can have a sizable impact on the clear-sky greenhouse effect.

Water can manifest itself also in the form of cirrus clouds, and cirrus cloud feedback is the major source of discrepancy between models of climate predictions. The prevalence and persistence of cirrus cloud systems, especially in the tropical upper troposphere, implies that cirrus clouds play an important role in climate (Liou, 1986). Radiative studies of cirrus clouds show that the clouds may cool radiatively or heat the upper atmosphere in the thermal infrared wavelengths, depending on the height, thickness and microphysics of the particles (Cox, 1971; Stephens et al., 1990). Cirrus clouds have been recognised as important components of feedback processes in the climate system (Randall et al., 1989; Del Genio et al., 1996; Chou and Neelin, 1999). Nevertheless, the available operative sensors give no direct information on cloud microphysics and cirrus clouds represent a major observational gap.

In this context, in June 2005, the first wideband spectrallyresolved measurements of the atmospheric thermal emission, including the FIR portion, were performed from a stratospheric balloon platform. Two experiments flew at almost the same time: the FIRST (Far InfraRed Spectroscopy of the Troposphere) experiment flew from Fort Sumner (NM, USA) on 7 June, and the REFIR-PAD (Radiation Explorer in the Far InfraRed - Prototype for Applications and Development) experiment flew in tropical region near Teresina in the North-East of Brazil on 30 June. FIRST measurements were performed with a broad bandpass Fourier transform spectrometer (FTS) using a Michelson configuration, and covered the $50-2000 \mathrm{~cm}^{-1}$ spectral range with a resolution of $0.625 \mathrm{~cm}^{-1}$. The instrument is partially cooled: aft optics at $180 \mathrm{~K}$, and detectors at $4.2 \mathrm{~K}$.

REFIR-PAD measurements, described in Sect. 2, were performed using an FTS with a Mach-Zehnder configuration that covered the $100-1400 \mathrm{~cm}^{-1}$ spectral range with a resolution of $0.475 \mathrm{~cm}^{-1}$. As described in Sect. 3, this spectral measurement enabled us to perform the retrieval of temperature and water vapour vertical profiles up to the upper troposphere level. A comparison of our results with the atmospheric state obtained from the ECMWF (European Centre for Medium-range Weather Forecast) analysis is shown in Sect. 4. In Sect. 5, the difference from the ECMWF result found in the water vapour concentration profile is used to address the effect on the calculation of the outgoing longwave radiation flux at the flight altitude level. Conclusions are reported in Sect. 6.

\section{Spectroscopic measurements of the outgoing long- wave radiation}

REFIR-PAD is a prototype that was developed as a field demonstrator of a satellite instrument designed within the framework of the European REFIR space mission (Rizzi et al., 2000, 2002). It is a compact and innovative FTS with a double-input/double-output port configuration that was designed for measuring with high accuracy the wideband atmospheric emission without requiring any cooled components (Palchetti et al., 2005; Bianchini et al., 2006). This instrument is optimised as a small and light payload, and uses uncooled optics and detectors. Uncooled detectors have an advantage in terms of size, weight and flexibility of applications. The capability of an uncooled instrument to provide information on the state of the atmosphere and its radiative properties is assessed in the present paper.

REFIR-PAD acquired 540 nadir spectra of the atmospheric emission during a stratospheric flight performed at a mean floating altitude of $34 \mathrm{~km}$ and that lasted for about $8 \mathrm{~h}$ (Palchetti et al., 2006). The experiment was launched onboard a gondola that hosted the LPMAA IASI-balloon (Laboratoire de Physique Moléculaire pour l'Atmosphère et l'Astrophysique - Infrared Atmospheric Sounding Interferometer) instrument from the airfield of Timon, near Teresina in north-east Brazil $\left(5^{\circ} 5^{\prime} \mathrm{S}, 42^{\circ} 52^{\prime} \mathrm{W}\right)$, at night at 03:36 local time. It landed $10 \mathrm{~h}$ later, $270 \mathrm{~km}$ south-west of the launch site. This tropical flight was performed within the framework of the Equatorial Large Balloons Campaign (ELBC) headed by the French Centre National d'Etudes Spatiales (CNES), in collaboration with the European Space Agency (ESA), for the Envisat (Environmental Satellite) validation program.

A summary of the main instrument specifications, including performances for this flight, is reported in Table 1.

An accurate characterisation of the Level 1 data analysis, that produced calibrated spectra, can be found in Bianchini and Palchetti (2008). The noise equivalent spectral radiance (NESR) due to the detector noise was found to be in the range of $0.8-2.5 \mathrm{~mW} /\left(\mathrm{m}^{2} \mathrm{srcm}^{-1}\right)$ for a single spectrum, with the lower values being between 200 and $600 \mathrm{~cm}^{-1}$. The mean calibration error was about $0.1 \mathrm{~K}$, with a peak-to-peak value of about $\pm 0.3 \mathrm{~K}$. Calibration measurements are performed every 10 nadir observations. Each set of nadir and calibration measurements lasts about $6 \mathrm{~min}$ and is identified as a sequence of measurements. A mean nadir spectrum is calculated for each sequence. The total radiometric error of each mean spectrum was calculated as a function of frequency 
taking into account both the detector noise and the systematic calibration errors.

\section{Retrieval of water vapour and temperature vertical profiles}

Nadir wideband spectral measurements are used to retrieve the vertical profiles of the atmospheric temperature and water vapour concentration and the surface (skin) brightness temperature (BT). The vertical temperature profile is retrieved exploiting the carbon dioxide band at $668 \mathrm{~cm}^{-1}$. Constant, trend-corrected values of carbon dioxide of $375 \mathrm{ppmv}$ in stratosphere and of $378 \mathrm{ppmv}$ in troposphere are used. The water vapour profile is retrieved exploiting both the rovibrational band and the FIR pure rotational band below $600 \mathrm{~cm}^{-1}$. The forward model and the inverse model of the retrieval code used for the analysis of the REFIR-PAD measurements are described in the following subsections.

\subsection{Forward model}

The forward model simulates REFIR-PAD wideband measurements by using line-by-line radiative transfer (RT) calculation. The code computes the radiance that reaches the instrument and simulates the instrumental effects (instrumental lineshape and field of view). The RT is performed by using the Curtis-Godson approximation (Houghton, 2002), which uses for each atmospheric layer and each species an equivalent value of temperature and pressure to calculate the mean cross-section. The atmospheric lineshape is modelled with a modified Voigt profile in which the Lorentz function is replaced by the Van Vleck-Weisskopf (Van Vleck and Weisskopf, 1945) function. The latter function is a rigorous model of the collisional broadening effect. This rigorous model is important at low frequencies where the Lorentz approximation, valid when the half width is much smaller than the central frequency of the line, does not apply. Therefore the Van Vleck-Weisskopf correction is not necessary for most of the fitted spectrum, but given its small computational cost is used at all frequencies. The spectroscopic database used for the simulations is the HITRAN 2004 (Rothman et al., 2005) with recent updates for the air-broadened half widths provided by Gordon et al. (2007). The atmospheric continuum is modelled according to Clough et al. (2005) (version MT_CKD_1.2, http://rtweb.aer.com/continuum_frame.html), which accounts for the contribution of water vapour lines external to the region of $\pm 25 \mathrm{~cm}^{-1}$ from the line centre. For $\mathrm{CO}_{2}$, a dedicated database and lineshape is adopted in order to take the line-mixing effect into account (Niro et al., 2005a,b).
Table 1. REFIR-PAD specifications and single spectrum performances.

\begin{tabular}{ll}
\hline Spectrometer specifications & \\
\hline Interferometer type & $\begin{array}{l}\text { Mach-Zehnder } \\
\text { with double-input/double-output }\end{array}$ \\
Detector system & 2 room-temperature DLATGS \\
Spectral coverage & $100-1400 \mathrm{~cm}^{-1}$ \\
Spectral resolution & $0.475 \mathrm{~cm}^{-1}$ \\
Optical throughput & $0.01 \mathrm{~cm}^{2} \mathrm{sr}$ \\
Field of view & $0.133 \mathrm{rad}^{-1}$ \\
Line of sight & nadir, limb and "deep" space \\
& at $+30^{\circ}$ elevation angle \\
Acquisition time & $32 \mathrm{~s}$ \\
NESR (in 100-1000 cm & $0.8-2.5 \mathrm{~mW} /\left(\mathrm{m}^{2} \mathrm{srcm} \mathrm{cm}^{-1}\right)$ \\
Mean calibration error & $0.1 \mathrm{~K}$ \\
\hline
\end{tabular}

\subsection{Inversion}

The retrieval procedure (Carli et al., 2007) uses the constrained non-linear least-square fit approach: the cost function to be minimised takes into account the a priori information (optimal estimation approach) and the Marquardt lambda parameter (Rodgers, 2000). The retrieval algorithm enables us to fit the wideband spectrum so as to find more quantities simultaneously (multi-target retrieval). Moreover, this method also allows a better handling of the errors due to the interfering unknowns.

REFIR-PAD measurements were analysed by simultaneously fitting the water vapour profile, the temperature profile and the Earth skin BT, using the spectrum from 100 to $1000 \mathrm{~cm}^{-1}$. The seasonal climatological database for initial guess (IG2) provided by Remedios (1999) for an equatorial atmosphere in July 2005 was used as a priori information. The pressure profile at the altitude grid provided by ECMWF database was obtained by imposing the hydrostatic equilibrium with a pressure reference level at $1000 \mathrm{hPa}$. The a priori errors that were used were: $100 \%$ for the water vapour profile and a linearly decreasing error from $9.8 \mathrm{~K}$ at an altitude of $1 \mathrm{~km}$ to $2.3 \mathrm{~K}$ at an altitude of $33 \mathrm{~km}$ for the temperature profile. The convergence was established using the chi-square test. The final reduced chi-square close to unity indicates the agreement between the forward model and measurements and the correctness of the estimated measurement noise. As an example Fig. 1 shows the comparison of the mean measured spectrum of sequence \#50 with the modelled spectrum. In the bottom panel the residual differences are compared with the NESR of the mean spectrum.

The temperature and the water vapour profiles measured by REFIR-PAD around noon UTC are compared with existing nearby radiosonde measurements and ECMWF estimates in Fig. 2 and Fig. 3, respectively. In the case of temperature the radiosondes provide a consistent set of measurements that 


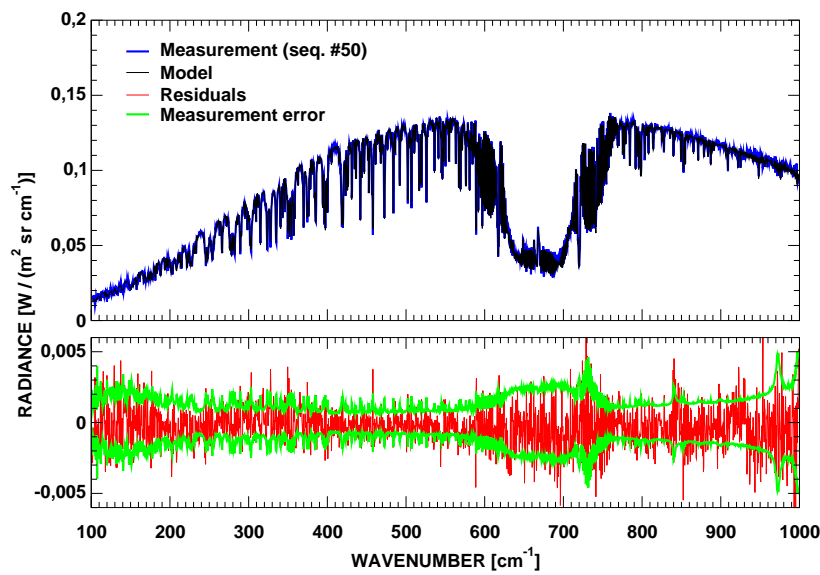

Fig. 1. Comparison between the measurement spectrum and the modelled spectrum (top panel, blue and black lines, respectively). In the bottom panel the residual difference (red line) is compared with the total measurement error (green line) using an enlarged scale. The mean spectrum of sequence \#50 is here shown.

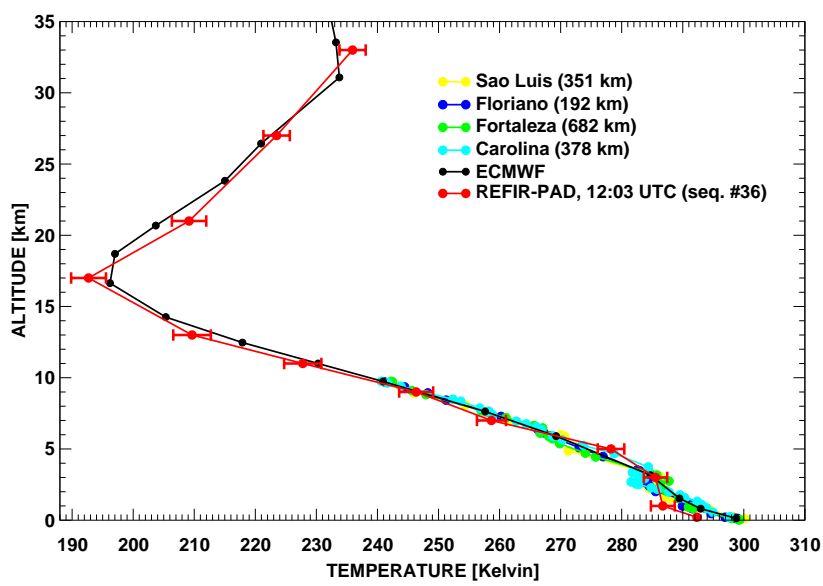

Fig. 2. Retrieval of the temperature vertical profile (red line) and comparison with the ECMWF profile (black line) and the existing nearby radiosondes (coloured dots). In parenthesis the distance of each radiosounding station from REFIR-PAD. For best coincidence with radiosoundings the profile for sequence \#36 measured around noon UTC is reported.

is well reproduced by ECMWF estimates. The temperature profile obtained by REFIR-PAD is in reasonable agreement with the ECMWF estimates. On the other hand in the case of water vapour the radiosondes provide oscillating profiles that are limited to the altitude range $0-10 \mathrm{~km}$. In this altitude range the ECMWF estimate agrees with either the average or the largest values of radiosonde measurements. Above $10 \mathrm{~km}$ no radiosonde measurements exist for a comparison with ECMWF estimates. The water vapour profile obtained by REFIR-PAD is in reasonable agreement with the ECMWF

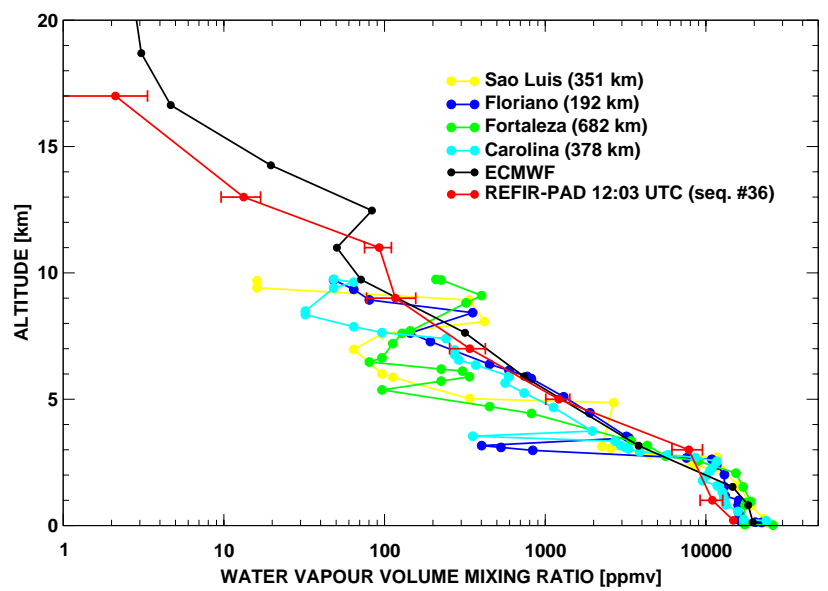

Fig. 3. Retrieval of the water vapour vertical profile (red line) and comparison with the ECMWF profile (black line) and the existing nearby radiosondes (coloured dots). In parenthesis the distance of each radiosounding station from REFIR-PAD. For best coincidence with radiosoundings the profile for sequence \#36 measured around noon UTC is reported.

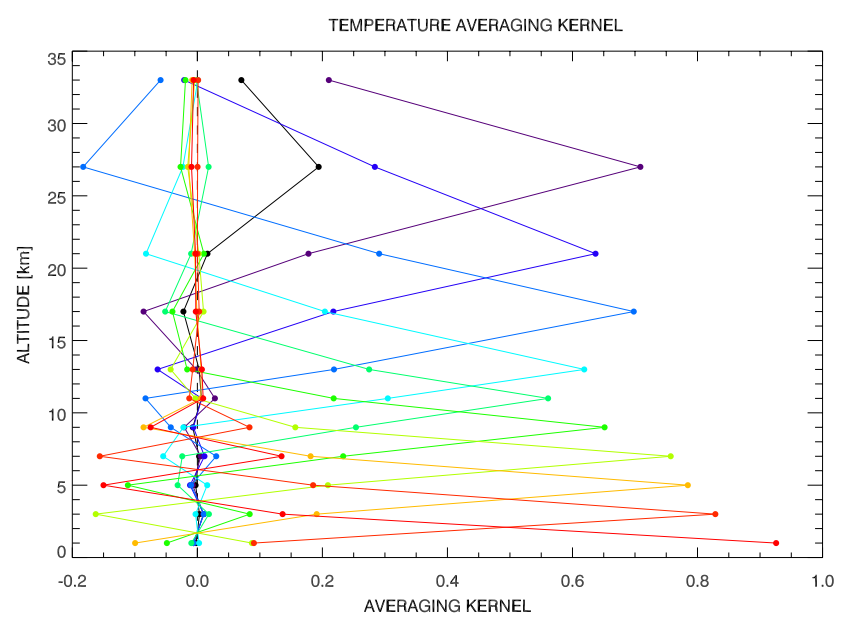

Fig. 4. Averaging kernels for temperature.

estimates below $10 \mathrm{~km}$, but differs significantly from it at higher altitudes. Since ECMWF provides a representation of the atmospheric state that is more complete than that provided by radiosoundings, the former will be considered in the subsequent analysis.

The retrieval altitude grid was optimised in order to maximise the total number of independent retrieved unknowns and to best exploit the sounding capability of the REFIRPAD instrument. The analysis of the averaging kernel profiles for temperature and water vapour VMR, shown in Fig. 4 and Fig. 5, respectively, was used to select the vertical retrieval grid. The results showed that the REFIR-PAD 


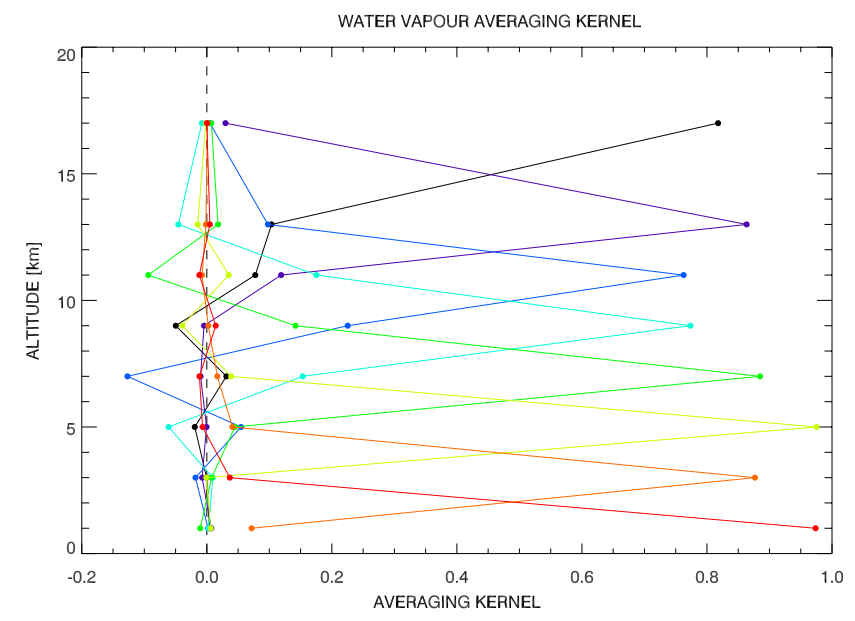

Fig. 5. Averaging kernels for water vapour.

measurements provided information up to $33 \mathrm{~km}$ for temperature and up to about $17 \mathrm{~km}$ for water vapour, with a vertical resolution in the lower troposphere of about $2 \mathrm{~km}$ for both quantities.

The degrees of freedom (DOF) of the retrieval are the number of independent new pieces of information and are measured by the trace values of the averaging kernel matrix. In our measurement we obtained 7 DOFs for both the atmospheric temperature and water vapour profiles plus $1 \mathrm{DOF}$ for the surface skin BT, thus resulting in a total of 15 DOFs. The information content coming from the FIR region improved the water vapour retrieval in the upper troposphere relative to retrievals performed only in the rovibrational band (Mertens, 2002).

\subsection{Error budget}

As already mentioned, the error analysis took into account both the random measurement noise (NESR) due to the detector and the spectrally-correlated calibration uncertainty. The NESR was in the $0.8-2.5 \mathrm{~mW} /\left(\mathrm{m}^{2} \mathrm{srcm}^{-1}\right)$ range for a single spectrum. The measurement noise of the calibration spectra also contributed to this error, which has no correlation among the different spectral channels. The effect of the calibration error was calculated, instead, from the peak error of $0.3 \mathrm{~K}$ in the measurement of the calibration sources temperature, and was estimated to be less than $1.2 \mathrm{~mW} /\left(\mathrm{m}^{2} \mathrm{srcm}^{-1}\right)$. This error is correlated among the different spectral channels. An in-depth analysis of the errors and of their spectral features can be found in Bianchini and Palchetti (2008).

A full variance-covariance matrix was used to assess the error propagation in the retrieved atmospheric state. An error of about $2 \mathrm{~K}$, constant at different altitudes, was thus found for the temperature profile and an error varying from $22 \%$ at ground to $35 \%$ at $17 \mathrm{~km}$ altitude for water vapour. These

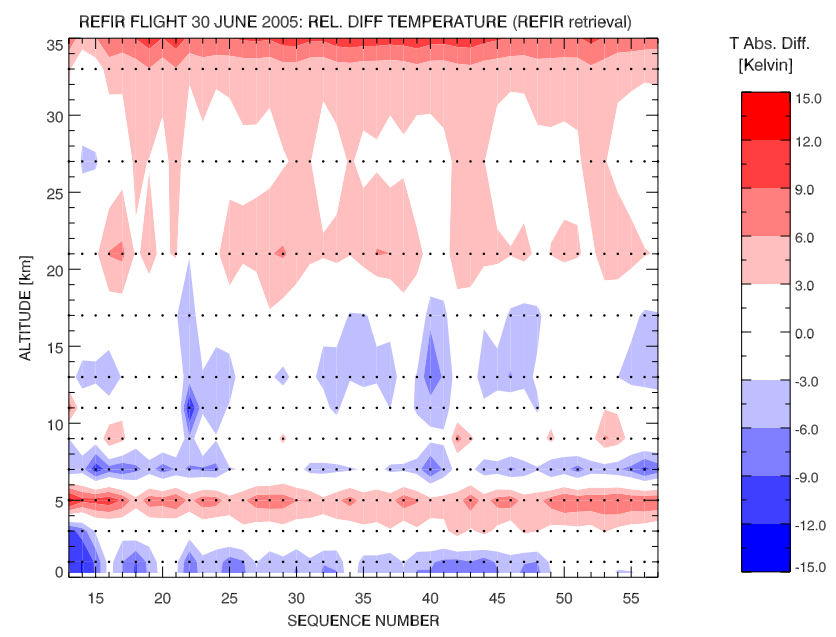

Fig. 6. Difference throughout the flight between the REFIR-PAD retrieved temperature and the ECMWF interpolated fields.

errors are shown, by means of error bars, in Figs. 2 and 3. The skin BT was retrieved with an error of about $0.4 \mathrm{~K}$.

\section{Data analysis: atmospheric state}

Some thin scattered clouds at low altitude were observed at the beginning of the flight by an infrared camera operating onboard the balloon gondola. For the remaining part of the flight no clouds were observed. The vertical profiles of water vapour VMR and temperature and the skin $\mathrm{BT}$ are retrieved for each measurement sequence from 08:05 to 15:48 UTC. The presence of low altitude clouds at the beginning of the flight gave only a small but detectable effect in the analysis of a few sequences (see the following Fig. 6 and 7).

We rely on correlative data obtained from ECMWF operational analysis to verify the quality of the vertical temperature and water vapour profiles retrieved from the REFIR-PAD measurements. Vertical profiles of temperature and relative humidity (converted to water vapour VMR) for the region of Teresina, Brazil and for the duration of the balloon flight are obtained from the ECMWF data archives. They have a spatial resolution of $1^{\circ} \times 1^{\circ}$ in latitude and longitude and a temporal resolution of $6 \mathrm{~h}$. These profiles are linearly interpolated to the average geolocation and time of each REFIRPAD sequence.

The REFIR-PAD profiles retrieved during the flight are compared with the ECMWF correlative data in Fig. 6 for temperature and in Fig. 7 for water vapour. The differences in temperature are generally small: namely, they seldom exceeded $6 \mathrm{~K}$. On the other hand for the water vapour VMR, as shown in Fig. 7, the retrieved profiles are characterised by an upper troposphere that is drier, by more than a factor 2, than ECMWF estimates. The differences observed at the 


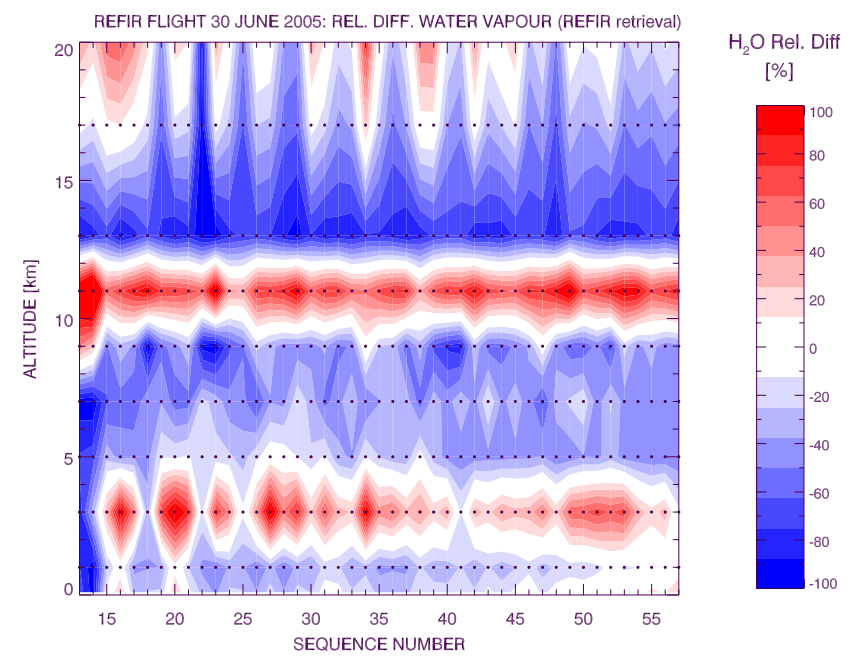

Fig. 7. Difference between water vapour VMR retrieved from the REFIR-PAD and the ECMWF interpolated fields.

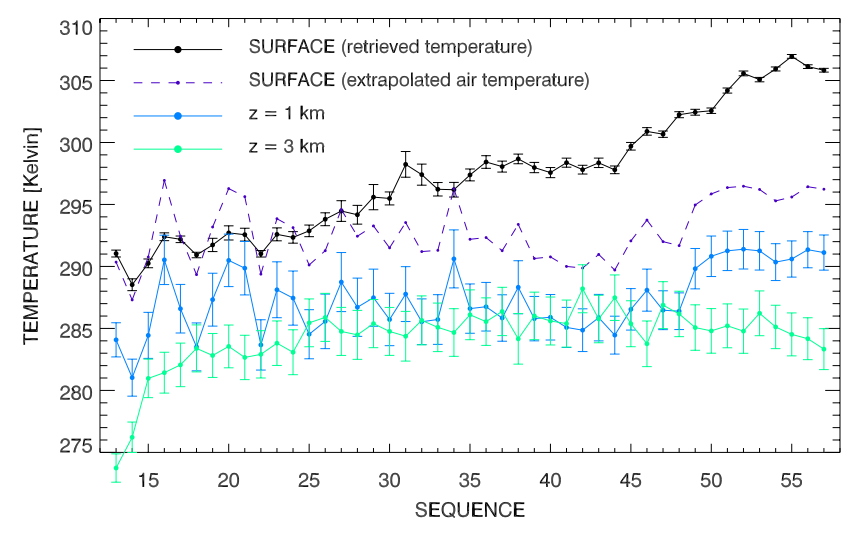

Fig. 8. Time series of temperature values as measured by REFIR at the surface (surface brightness temperature) and at the retrieval altitudes of 1.0 and $3.0 \mathrm{~km}$.

beginning of the flight, for sequence numbers equal to 13,14 and 22 , are probably due to a pixel contamination produced by the presence of clouds.

The time series of the retrieved temperature values for the lower troposphere can be seen in Fig. 8. A skin BT increment due to solar irradiation is detected, starting from the sunrise occurring at sequence \#19. A small increase in temperature is also observed in the lowest layers of the atmosphere.

Apart from the warming of the lowest atmospheric layers, the other retrieved values do not show a detectable trend, so that an average profile can be calculated for the atmosphere observed during the flight. Table 2 and 3 show the average retrieved profiles of temperature and water vapour, respectively, together with the standard deviation of the ensemble and the average retrieval error. The latter two quantities are in good agreement, even if larger values are observed for the standard deviation at low altitudes and for the retrieval error at high altitudes. We note that, while the random measurement errors contribute to both error estimates, the atmospheric variability contributes only to the standard deviation and the systematic calibration error contributes only to the retrieval error. This suggests that superimposed to the random errors, for which the two error estimates provide consistent evaluations, we may be observing the effects of atmospheric variability at low altitudes and of systematic calibration errors at high altitudes.

The measurement error that has been verified by this comparison can be compared with the difference between measured and ECMWF profiles, given in the fifth column. In order to facilitate the comparison, the ratio between the values of the fifth column and the largest between the values given in the third and fourth columns is given in the sixth column. Since the measurement error is the main error source, the largest of the two errors is an approximate but reasonable estimate of the overall error budget that includes measurement error, calibration error and atmospheric variability. The qualitative comparison made in Fig. 2 and Fig. 3 can now be discussed in a more quantitative manner.

In the case of the temperature profile consistent results are observed. Indeed the differences are only marginally larger than the error of the retrieved profile and can be explained by the following external errors: ECMWF errors (estimated to vary between 1 and $3 \mathrm{~K}$ ), spectroscopic errors (estimated to be equal to a few percents), and smoothing errors due to the discrete sampling of a distribution with a vertical variability.

In the case of the water vapour profile different considerations apply at different altitudes. In the lower atmosphere (at $11 \mathrm{~km}$ and below) consistent results are observed and the few large differences can be explained by the smoothing error. Indeed for water vapour, because of its large vertical variations, the smoothing error is expected to have more pronounced effects than for temperature. On the other hand, a large disagreement is observed at $13 \mathrm{~km}$. In order to explain this disagreement, the effect of cirrus clouds, water vapour continuum and spectroscopic errors have been investigated.

When cirrus clouds are included in our atmospheric model, the retrieved column of ice particles turned out to have an average value throughout the flight of about $1 \mu \mathrm{g} / \mathrm{cm}^{2}$ with an r.m.s. of $16 \mu \mathrm{g} / \mathrm{cm}^{2}$. No detectable change was observed in the retrieved water vapour and temperature profiles when cirrus clouds are fitted. Therefore, the error introduced by the assumption of no cirrus clouds is negligible.

A stringent validation is lacking for the water vapour continuum absorption model, however the Jacobian calculations indicate that this quantity does mainly influence the retrieval of water vapour below $7 \mathrm{~km}$ where smaller discrepancies are observed. The retrieved value at $13 \mathrm{~km}$ directly depends on the spectroscopy of water vapour; however the spectroscopy cannot account for a difference as large as the one observed. Also considering that the chi-square test provided values that 
Table 2. Average profile of temperature and errors.

\begin{tabular}{rrrrrr}
\hline $\begin{array}{r}\text { Altitude } \\
{[\mathrm{km}]}\end{array}$ & $\begin{array}{r}\text { Mean Temp. } \\
{[\mathrm{K}]}\end{array}$ & $\begin{array}{r}\text { Retrieval Err. } \\
{[\mathrm{K}]}\end{array}$ & $\begin{array}{r}\text { Std.Dev. } \\
{[\mathrm{K}]}\end{array}$ & $\begin{array}{r}\text { REFIR-ECMWF } \\
{[\mathrm{K}]}\end{array}$ & Ratio (see text) \\
\hline 33 & 236.0 & 1.9 & 0.8 & 2.6 & 1.4 \\
27 & 222.7 & 2.0 & 1.6 & 0.2 & 0.1 \\
21 & 207.3 & 2.7 & 1.5 & 2.1 & 0.8 \\
17 & 193.3 & 2.7 & 2.1 & -2.5 & -0.9 \\
13 & 209.9 & 2.9 & 1.7 & -4.4 & -1.5 \\
11 & 228.3 & 2.9 & 2.7 & -2.0 & -0.7 \\
9 & 246.5 & 2.7 & 2.3 & -0.2 & -0.1 \\
7 & 255.5 & 2.2 & 2.2 & -6.3 & -2.9 \\
5 & 279.6 & 2.0 & 1.8 & 5.6 & 2.8 \\
3 & 283.6 & 1.8 & 2.5 & -1.3 & -0.5 \\
1 & 287.4 & 1.9 & 2.6 & -5.5 & -2.1 \\
\hline
\end{tabular}

Table 3. Average profile of water vapour and errors.

\begin{tabular}{rrrrrr}
\hline $\begin{array}{r}\text { Altitude } \\
{[\mathrm{km}]}\end{array}$ & $\begin{array}{r}\text { Mean } \mathrm{H}_{2} \mathrm{O} \\
{[\mathrm{ppmv}]}\end{array}$ & $\begin{array}{r}\text { Retrieval Err. } \\
{[\mathrm{ppmv}]}\end{array}$ & $\begin{array}{r}\text { Std.Dev. } \\
{[\mathrm{ppmv}]}\end{array}$ & $\begin{array}{r}\text { REFIR-ECMWF } \\
{[\mathrm{ppmv}]}\end{array}$ & Ratio (see text) \\
\hline 17 & 3.1 & 1.2 & 1.1 & -1.4 & -1.2 \\
13 & 11.5 & 3.8 & 5.2 & -51.2 & -9.8 \\
11 & 94 & 19 & 12 & 43 & 2.3 \\
9 & 93 & 57 & 46 & -65 & -1.1 \\
7 & 303 & 111 & 87 & -172 & -1.6 \\
5 & 1320 & 200 & 290 & -590 & -2.0 \\
3 & 7800 & 1400 & 2300 & 2400 & 1.0 \\
1 & 14200 & 2800 & 3200 & -2900 & -0.9 \\
\hline
\end{tabular}

varied between 0.9 and 1.5 , we conclude that no evidence can be found in our measurements for a significant unaccounted systematic error that can explain the discrepancy observed at $13 \mathrm{~km}$. This suggest the possibility of an over estimate of water vapour in the ECMWF model at high altitudes.

The agreement between observations and retrieval model, that is suggested by the chi-square test, is confirmed by the behaviour of the residuals. In Fig. 9, we report the mean values of the residuals of the fitting process (red line) compared with the mean value of the measurement error over the flight. The residuals are generally well within the mean measurement error, proving that systematic errors give a negligible effect in the fitting procedure of a single spectrum. The isolated exceptions of the peaks at around $460 \mathrm{~cm}^{-1}$ and $590 \mathrm{~cm}^{-1}$ are due to the non-fitted concentrations of, respectively, $\mathrm{HNO}_{3}$ and $\mathrm{N}_{2} \mathrm{O}$ which were assumed to be equal to the climatological value (Bianchini et al., 2007).

\section{Data analysis: outgoing longwave radiation flux}

The evaluation of the OLR by using non-spectral single view observations is affected by errors due to radianceto-flux conversion. The angular distribution model, that

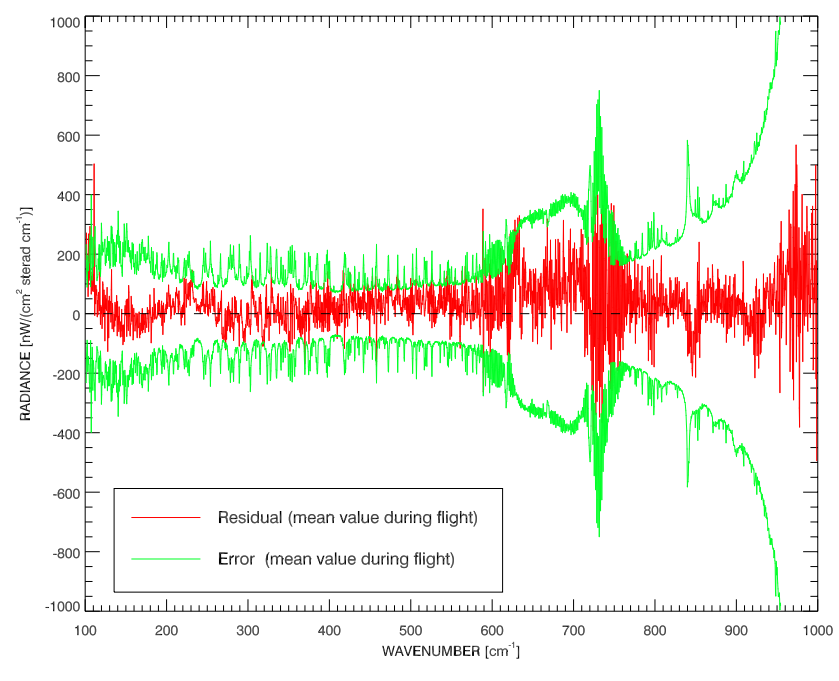

Fig. 9. Mean value of residuals and error during the flight.

this kind of measurements uses for the calculation of OLR, see e.g. ERBE (Earth Radiation Budget Experiment) (Suttles et al., 1992) and CERES (Clouds and Earth's 


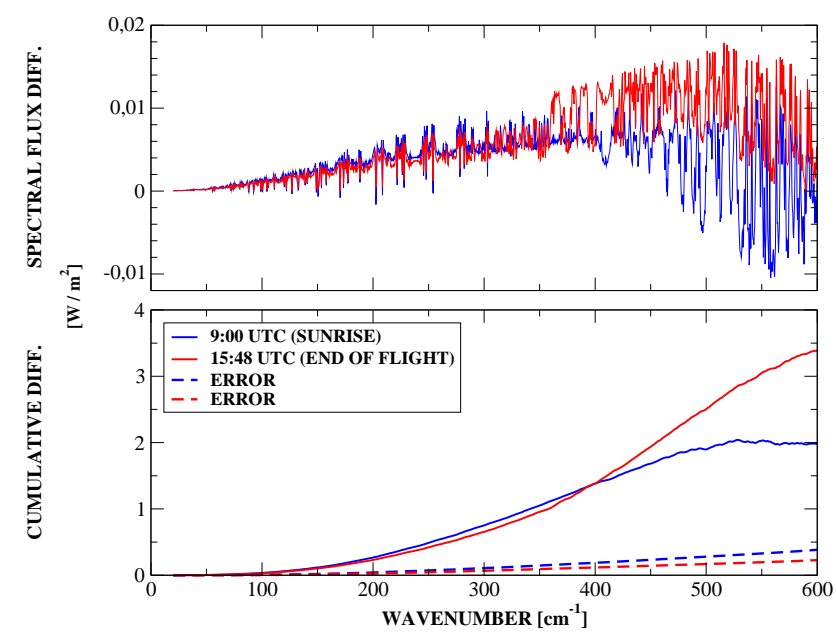

Fig. 10. Difference between the spectral fluxes calculated for the fitted and ECMWF water vapour and temperature profiles. The figure shows the results of 2 sequence measurements reported as a function of wavenumber (top panel). The cumulative integral is shown in the bottom panel.

Radiant Energy System) (Wielicki et al., 1996) experiments, is typically affected by an error of about $4.6 \mathrm{~W} / \mathrm{m}^{2}$ (Clerbaux et al., 2003).

Our spectrally resolved measurement provided an opportunity to retrieve the atmospheric parameters that primarily determine the OLR emission, i.e. the vertical profiles of temperature and water vapour and the surface emission. Based on this information and using a RT model such as the one described in Sect. 3.1, we are able to simulate the emission $L(\sigma, \theta)$ as a function of the wavenumber $\sigma$ and the zenith angle $\theta$. In the case of a horizontally uniform atmosphere, the OLR flux $F_{\text {OLR }}$ can be calculated by means of the following equation:

$F_{\mathrm{OLR}}=2 \pi \int_{0}^{\infty} d \sigma \int_{0}^{\frac{\pi}{2}} L(\sigma, \theta) \cos (\theta) \sin (\theta) d \theta$

and has a variance equal to:

$$
\begin{aligned}
\sigma_{F_{\mathrm{OLR}}}^{2} & =4 \pi^{2} \int_{0}^{\infty} d \sigma_{1} \int_{0}^{\infty} d \sigma_{2} \int_{0}^{\frac{\pi}{2}} d \theta_{1} \cos \left(\theta_{1}\right) \sin \left(\theta_{1}\right) \\
& \cdot \int_{0}^{\frac{\pi}{2}} d \theta_{2} \cos \left(\theta_{2}\right) \sin \left(\theta_{2}\right) \mathbf{J}_{1} \mathbf{S J}_{2}^{T} .
\end{aligned}
$$

$\mathbf{S}$ is the variance-covariance matrix of the retrieved atmospheric parameters, $\mathbf{J}_{1}$ and $\mathbf{J}_{2}$ are the Jacobian matrices defined as:

$$
\left(\mathbf{J}_{k}\right)_{\sigma_{i}, j}=\frac{\partial L\left(\sigma_{i}, \theta_{k}\right)}{\partial x_{j}}
$$

where $x_{i}$ are the retrieved parameters.
Equation (1) was used for the calculation of $F_{\mathrm{OLR}}$ at the floating altitude of the balloon gondola. The integral was calculated with a spectral integration from 20 to $2600 \mathrm{~cm}^{-1}$ and with the simulation of different angular observations from the zenith to the atmospheric limb. The limitation in the spectral domain introduces an underestimation of about $0.05 \mathrm{~W} / \mathrm{m}^{2}$ in our case of the tropical atmosphere. The OLR flux varied along the flight path mainly because of the temperature variations of the lower troposphere and of the Earth surface. The value had a minimum of $284 \mathrm{~W} / \mathrm{m}^{2}$ at sunrise, which occurred at 09:00 UTC, and reached $306 \mathrm{~W} / \mathrm{m}^{2}$ at the end of the flight, at 15:48 UTC. The error analysis shows that the effect of random noise on the flux integral is negligible, since it has positive and negative contributions that cancels out along the wavenumber integration performed to calculate the flux. The systematic component due to the calibration accuracy is, instead, integrated with the flux, and is the main contribution to the total error. With this analysis, we find that the radiation flux error does not exceed $1.3 \mathrm{~W} / \mathrm{m}^{2}$.

A comparison with the fluxes calculated from the ECMWF atmospheric states was performed in the two extreme cases at sunrise and at the end of the flight. The fluxes obtained with the ECMWF atmosphere also show an increase with time, but both the ECMWF fluxes and their increase are less than what is obtained using REFIR-PAD data. For a comparison between ECMWF and REFIR-PAD, we focus our attention to the spectral region from 20 to $600 \mathrm{~cm}^{-1}$ where the new observations have been made. Furthermore, this spectral region is less affected by low altitude clouds than the window region between 800 and $1000 \mathrm{~cm}^{-1}$. In practice no significant emission is observed below $4 \mathrm{~km}$ in the spectral region between 0 and $400 \mathrm{~cm}^{-1}$. The result is shown in Fig. 10, where in the top panel the differences between the spectral fluxes calculated from the retrieved water vapour and temperature profiles and the ECMWF profiles are shown for the sunrise (blue line) and for the end of the flight (red line). In the bottom panel, the results are reported as the cumulative integral of the spectral differences, and are compared with the cumulative integral of the expected error (dashed lines). The OLR flux differences in the FIR are in the range of $2-3.5 \mathrm{~W} / \mathrm{m}^{2}$, where the largest difference is in the case of the warmer atmosphere observed during the daytime with respect to the nighttime. The error on our flux measurement is about $0.4 \mathrm{~W} / \mathrm{m}^{2}$ when calculated for this spectral range. Further unaccounted errors are the ECMWF uncertainties and the smoothing error, while spectroscopic errors are expected to be negligible because of the opposite effects in the forward model and inversion calculations.

This result clearly identifies the differences between radiance measurements and the estimations made using the ECMWF atmospheric analysis and underlines the importance of the characterisation of the FIR region for an exact calculation of the OLR fluxes. The error with which our flux is determined is caused mainly by calibration uncertainties, while detector noise has a negligible effect. This is a further 
demonstration that uncooled detectors are adequate for detailed radiometric observations.

\section{Conclusions}

The results of the first flight performed by REFIR-PAD in June 2005 in tropical region have been shown. The instrument measured spectra of the outgoing longwave radiation from 100 to $1400 \mathrm{~cm}^{-1}$. This spectrally resolved measurement made possible the retrieval of the atmospheric state with sufficient precision to improve the accuracy with which the integrated outgoing radiation flux can be calculated, proving that spectral information can be used to infer the angular distribution of radiance.

While the temperature profile is in reasonable agreement with the ECMWF analysis, the retrieved water vapour VMR profile differs by about a factor 2, particularly in the upper troposphere. The different atmospheric states obtained by ECMWF and REFIR-PAD are found to be responsible for a different estimation of the OLR flux. We find that the OLR fluxes calculated using our measurements and the ECMWF estimates differ by $2-3.5 \mathrm{~W} / \mathrm{m}^{2}$. This calculation is made at the flight altitude of $34 \mathrm{~km}$ and in the FIR spectral region (in the $20-600 \mathrm{~W} / \mathrm{m}^{2}$ interval). A difference of $3.5 \mathrm{~W} / \mathrm{m}^{2}$ is an important term in the determination of the total OLR, since it is comparable to or even greater than the estimate of the radiative forcing of the $\mathrm{CO}_{2}$ increases, recorded since preindustrial times.

Furthermore, we have observed that the error of our flux measurement is about $0.4 \mathrm{~W} / \mathrm{m}^{2}$ and is mainly due to radiometric calibration uncertainty, while the random detector noise has a negligible effect, thus proving the feasibility of climatological studies with instruments that use uncooled detectors.

This observation, which is limited in time and space, cannot be representative of a bias in ECMWF analysis, but emphasises a shortcoming in our knowledge of the Earth's radiation budget.

We argue that a comprehensive characterisation of the outgoing radiation flux can be attained even with uncooled detectors with spectrally-resolved wideband measurements of the atmospheric emission that also include the far infrared spectral region.

Acknowledgements. The authors wish to thank C. Camy-Peyret, LPMAA-CNRS, France, and the CNES team (led by P. Chadoutaud and J. Evrard) for having hosted the REFIR-PAD on-board the IASI-balloon gondola and for their helpful support during the Brazilian field campaign. The Authors also acknowledge ECMWF for providing data which were used in this work and the help given by E. Castelli (ISAC-CNR, Bologna).

Edited by: R. von Glasow

Reviewed by: two anonymous referees

\section{References}

Bianchini, G., Palchetti, L., and Carli, B.: A wide-band nadirsounding spectroradiometer for the characterization of the Earth's outgoing long-wave radiation, in: Proceedings of SPIE Vol. 6361, edited by: Meynart, R., Neeck, S. P., Shimoda, H., Systems and Next-generation Satellites XII, 63610A, 2006.

Bianchini, G., Carli, B., Cortesi, U., Bianco, S. D., Gai, M., and Palchetti, L.: Test of far infrared atmospheric spectroscopy using wide band balloon borne measurements of the upwelling radiance, J. Quant. Spectrosc. Ra., doi:10.1016/j.jqsrt.2007.11.010, 2007.

Bianchini, G. and Palchetti, L.: Technical Note: REFIR-PAD level 1 data analysis and performance characterization, Atmos. Chem. Phys. Discuss., 8, 367-401, 2008, http://www.atmos-chem-phys-discuss.net/8/367/2008/.

Carli, B., Bazzini, G., Castelli, E., Cecchi-Pestellini, C., Bianco, S. D., Dinelli, B. M., Gai, M., Magnani, L., Ridolfi, M., and Santurri, L.: MARC: A code for the retrieval of atmospheric parameters from millimeter-wave limb measurements, J. Quant. Spectrosc. Ra., 105, 476-491, 2007.

Chahine, M.: The hydrological cycle and its influence on climate, Nature, 359, 373-380, 1992.

Chou, C. and Neelin, J.: Cirrus Detrainment-Temperature Feedback, Geophys. Res. Lett., 26, 1295-1298, 1999.

Clerbaux, N., Dewitte, S., Gonzalez, L., Bertrand, C., Nicula, B., and Ipe, A.: Outgoing longwave flux estimation: improvement of angular modelling using spectral information, Remote Sens. Environ., 85, 389-395, 2003.

Clough, S. A., Iacono, M. J., and Moncet, J.-L.: Line-by-Line Calculations of Atmospheric Fluxes and Cooling Rates: Application to Water Vapor, J. Geophys. Res., 97, 15 761-15 785, 1992.

Clough, S. A., Shepard, M. W., Mlawer, E. J., Delamere, J. S., Iacono, M. J., Cady-Pereira, K., Boukabara, S., and Brown, P. D.: Atmospheric radiative transfer modelling: a summary of the AER codes, J. Quant. Spectrosc. Ra., 91, 233-244, 2005.

Cox, S.: Cirrus Clouds and the Climate, J. Atmos. Sci., 28, 15131515, 1971.

Del Genio, A. D., Yao, M.-S., Kovari, W., , and Lo, K. K.-W.: A prognostic cloud water parameterization for global climate models, J. Climate, 9, 270-304, 1996.

Gordon, I. E., Rothman, L. S., Gamache, R. R., Jacquemart, D., Boone, C., Bernath, P. F., Shephard, M. W., Delamere, J. S., and Clough, S. A.: Current updates of the water-vapor line list in HITRAN: A new "Diet” for air-broadened half-widths, J. Quant. Spectrosc. Ra., 108, 389-402, 2007.

Harries, J. E.: The Greenhouse Earth - A view from space, Q. J. Roy. Meteor. Soc., 122, 799-818, 1996.

Harries, J. E.: Atmospheric radiation and atmospheric humidity, Q. J. Roy. Meteor. Soc., 123, 2173-2186, 1997.

Held, I. M. and Soden, B. J.: Water vapor feedback and global warming, Annu. Rev. Energ. Env., 25, 441-475, 2000.

Houghton, J.: The physics of atmospheres, Cambridge University Press, Cambridge, U.K., New York, 2002.

Lindzen, R.: Some Coolness Concerning Global Warming, Bull. Amer. Meteor. Soc., 71, 288-299, 1990.

Liou, K.-N.: Influence of cirrus clouds on weather and climate processes, a global perspective, Mon. Weather Rev., 114, 11671199, 1986.

Mertens, C. J.: Feasibility of retrieving upper tropospheric water va- 
por from observations of far-infrared radiation, in: Proceedings of SPIE Vol. 4485, edited by: Larar, A. M. and Mlynczak, M. G., Optical Spectroscopic Techniques, Remote Sensing, and Instrumentation for Atmospheric and Space Research IV, 191-201, 2002.

Niro, F., Jucks, K., and Hartmann, J. M.: Spectra calculations in central and wing regions of $\mathrm{CO}_{2}$ IR bands. IV: software and database for the computation of atmospheric spectra, J. Quant. Spectrosc. Ra., 95, 469-481, 2005a.

Niro, F., Von Clarmann, T., Jucks, K., and Hartmann, J. M.: Spectra calculations in central and wing regions of $\mathrm{CO}_{2}$ IR bands between 10 and $20 \mu \mathrm{m}$. III: atmospheric emission spectra, J. Quant. Spectrosc. Ra., 90, 61-76, 2005b.

Palchetti, L., Bianchini, G., Castagnoli, F., Carli, B., Serio, C., Esposito, F., Cuomo, V., Rizzi, R., and Maestri, T.: Breadboard of the Fourier-transform spectrometer for the Radiation Explorer in the Far Infrared atmospheric mission, Appl. Optics, 44, 28702878, 2005.

Palchetti, L., Belotti, C., Bianchini, G., Castagnoli, F., Carli, B., Cortesi, U., Pellegrini, M., Camy-Peyret, C., Jeseck, P., and Té, Y.: Technical note: First spectral measurement of the Earth's upwelling emission using an uncooled wideband Fourier transform spectrometer, Atmos. Chem. Phys., 6, 5025-5030, 2006.

Pierrehumbert, R.: The hydrologic cycle in deep-time climate problems, Nature, 419, 191-198, 2002.

Randall, D. A., Harshvardhan, Dazlich, D. A., and Corsetti, T. G.: Interactions among Radiation, Convection, and Large-Scale Dynamics in a General Circulation Model, J. Atmos. Sci., 47, 19431970, 1989.

Randall, D., Wood, R., Bony, S., et al.: Climate Models and Their Evaluation, in: Climate Change 2007 - The Physical Science Basis, IPCC WG1 AR4 Final Report, 589-662, 2007.

Remedios, J. J.: Extreme atmospheric constituent profiles for MIPAS, Proceedings of the European Symposium on Atmospheric Measurements from Space, ESTEC, Netherlands, 20-22 January, 96, 779-783, 1999.

Rizzi, R., Bizzarri, B., Bonsignori, R., et al.: REFIR Radiation Explorer in the Far InfraRed, Final Tech. Rep. ENV4-CT6-0344, European Commission, Brussels, Belgium, 2000.

Rizzi, R., Palchetti, L., Carli, B., Bonsignori, R., Harries, J. E., Leotin, J., Peskett, S. C., Serio, C., and Sutera, A.: Feasibility of the spaceborne radiation explorer in the far infrared (REFIR), Proceedings of SPIE Vol. 4485, in: Optical Spectroscopic Techniques, Remote Sensing, and Instrumentation for Atmospheric and Space Research IV, edited by: Larar, A. M. and Mlynczak, M. G., 202-209, 2002.
Rodgers, C. D.: Inverse Methods for Atmospheric Sounding: Theory and Practice, Series on Atmospheric, Oceanic and Planetary Physics, 2, World Scientific, Singapore, 2000.

Rothman, L. S., Jacquemart, D., Barbe, A., Benner, D. C., Birk, M., Brown, L. R., Carleer, M. R., and Wagner, G.: The HITRAN 2004 molecular spectroscopic database, J. Quant. Spectrosc. Ra., 96, 139-204, 2005.

Sinha, A. and Harries, J. E.: Water vapor and greenhouse trapping: the role of far infrared absorption, Geophys. Res. Lett., 22, 21472150, 1995.

Stephens, G., Tsay, S., Stackhouse, P. J., and Flatau, P.: The Relevance of the Microphysical and Radiative Properties of Cirrus Clouds to Climate and Climatic Feedback, J. Atmos. Sci., 47, 1742-1754, 1990.

Stuber, N., Ponater, M., and Sausen, R.: Why radiative forcing might fail as a predictor of climate change, Clim. Dynam., 24, 497-510, 2005.

Suttles, J. T., Wielicki, B. A., and Vemury, S.: Top-of-Atmosphere Radiative Fluxes: Validation of ERBE Scanner Inversion Algorithm Using Nimbus-7 ERB Data, J. Appl. Meteor., 31, 784-796, 1992.

Tobin, D. C., Best, F. A., Brown, P. D., Clough, S. A., Dedecker, R. G., Ellingson, R. G., Garcia, R. K., Howell, H. B., Knuteson, R. O., Mlawer, E. J., Revercomb, H. E., Short, J. F., van Delst, P. F. W., and Walden, V. P.: Downwelling spectral radiance observations at the SHEBA ice station: Water vapor continuum measurements from 17 to $26 \mu \mathrm{m}$, J. Geophys. Res., 104, 2081-2092, 1999.

Van Vleck, J. H. and Weisskopf, V. F.: On the Shape of CollisionBroadened Lines, Revs. Mod. Phys., 17, 227-236, 1945.

Wielicki, B. A., Barkstrom, B. R., Harrison, E. F., Lee, R. B., Louis Smith, G., and Cooper, J. E.: Clouds and the Earth's Radiant Energy System (CERES): An Earth Observing System Experiment, Bull. Amer. Meteor. Soc., 77, 853-868, 1996. 